\section{Multimodalidade e hipertexto: uma análise do site Hora do ENEM}

\author{
Multimodality and hypertext: \\ an analysis of the site Hora \\ do ENEM
}

Marcela Regina Vasconcelos da Silva NASCIMENTO (UPE) marcela.vasconcelos@upe.br

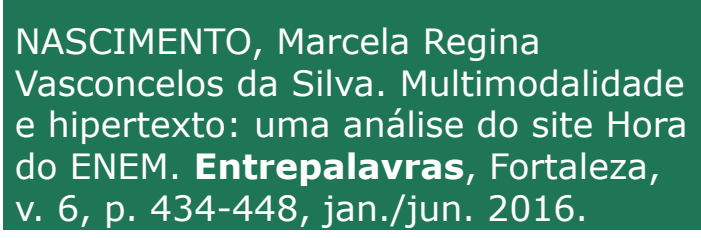

Resumo: Na sociedade atual, marcada pela ampliação da construção coletiva de conhecimentos, intensa troca de informações e alta conectividade, ganha relevo o caráter multimodal da comunicação. Com a proliferação de novos meios de comunicação, devido ao desenvolvimento de múltiplas tecnologias de informação, torna-se imprescindível discutir como multimodalidade e hipertexto interagem na construção de sentidos. Para tanto, analisamos o site Hora do ENEM, à luz dos estudos teóricos de Dionísio (2008, 2009), Dondis (2007), Kress; van Leeuwen (2006), Rojo (2009), Soares (2004), Vieira (2007). Os resultados obtidos ratificaram a ideia de que apenas o domínio do sistema linguístico não é suficiente para a construção de sentidos na leitura dos textos, tendo em vista que a presença de elementos multimodais nesses textos de ampla circulação social é significativa para a compreensão. Foi constatado que, uma vez que a utilização de signos verbais e recursos visuais, além de relevante para os efeitos de sentido, são considerados mais atraentes e mais informativos pelos leitores letrados, poderia haver, no site Hora do ENEM, um investimento maior no diálogo entre recursos verbais e não verbais.

Palavras-chave: Hipertexto. Multimodalidade. Imagem. 


\begin{abstract}
In current society, characterized by the coletive knowledge construction, intense information Exchange and high conectivity, gains attention the multimodal character of communication. With the spread of new communication ways, due to the development of multiple kinds of information technology, it becomes necessary to discuss how multimodality and hypertext interacts in the construction of senses. For that we have analyzed the website Hora do ENEM, in the light of the theoretical studies of Dionysus (2008, 2009), Dondis (2007), Kress; Van Leeuwen (2006), Rojo (2009), Soares (2004), Vieira (2007). The results obtained ratified the idea that only the domain of the linguistic system is not sufficient for the construction of meanings in the reading of the texts, considering that the presence of multimodal elements in these texts of wide social circulation is significant for the understanding. It was found that, since the use of verbal signs and visual resources, in addition to being relevant to the effects of meaning, are considered more attractive and more informative by the literate readers, there could be, on the Hora do ENEM website, a greater investment in dialogue between verbal and non-verbal resources.
\end{abstract}

Keywords: Hypertext. Multimodality. Image.

\title{
Introdução
}

Durante muito tempo, a leitura foi considerada apenas como a decodificação de elementos linguísticos na superfície textual, limitando-se, portanto, à linguagem verbal. No entanto, diversos estudos linguísticos têm apontado a necessidade de desenvolver uma leitura crítica, que possa ir além dos limites do que está dito, visando à construção de sentidos de maneira global. Para tanto, além de considerar a importância de implícitos, processos de inferenciação, entre outros, convém analisar os elementos multimodais, visto que, desde a infância, os leitores estão em contato com variados gêneros do discurso nos quais cores, imagens, sons se integram aos elementos verbais na construção de sentidos.

Para que haja a leitura crítica desses gêneros, é imprescindível, pois, considerar a relevância de imagens, cores e outros elementos significativos, para possibilitar práticas de letramentos além do sistema da escrita. Isso se torna cada vez mais importante, pois os avanços tecnológicos têm permitido a produção de textos com uma enorme variedade de formas, os quais circulam em diferentes situações sociais e com objetivos diversos, possibilitando uma maior liberdade de manipulação dos gêneros do discurso. Com o passar do tempo, intensificaram-se os usos de recursos multimodais, provocando mudanças no processo de construção de textos, o que acarreta mudanças nas formas de leitura.

A existência de gêneros discursivos em que o verbal e o não verbal articulam-se em um todo significativo é cada vez mais fecunda, e 
v. 7 (1)

434-448

jan/jun

2017

a leitura desses gêneros, que se caracterizam como textos multimodais, propicia a ampliação do conceito de leitura. Conceito esse que já vem sendo ampliado em virtude do estudo do hipertexto, que, segundo Cavalcante (2004, p. 163),

[...] surge como a possibilidade de discutir a textualidade à luz de teorias textuais e também cognitivas, num portador de texto, o hipertexto, disponibilizado num veículo com especificidades próprias como se configura a Internet.

Essas especificidades têm levado ao reconhecimento de uma leitura não linear, multidimensional e não hierarquizada, já que "o hipertexto constitui-se como um suporte capaz de congregar muitas mídias (som, imagem, escrita), transformando-se numa ferramenta hipermidiática" (CAVALCANTE, 2004, p. 163).

Diante disso, este trabalho tem como objetivo investigar a multimodalidade na leitura de um hipertexto. Assim, foi feita uma revisão de estudos teóricos pertinentes à abordagem do tema e, em seguida, foi selecionado o site Hora do ENEM, para compor o corpus desta pesquisa. Em decorrência, o corpus é constituído por 6 (seis) imagens printadas, escolhidas em virtude da relevância e do destaque dessas imagens no site analisado. Assim, as quatro primeiras figuras analisadas nesta pesquisa se referem a elementos colocados na página inicial (home) do site Hora do ENEM (três delas mostram o conteúdo do slide show existente na tela inicial, elemento que, em virtude de sua localização na parte alta da tela e em função do caráter dinâmico da apresentação, consiste no item de maior destaque no site), ao passo que as duas últimas imagens representam telas relativas ao conteúdo a que se tem acesso clicando em um dos links da barra de menu presente na parte superior do site.

A escolha deste site se deu em função do fato de que ele se constitui como uma iniciativa governamental, fruto de uma parceria entre o Ministério da Educação, o Serviço Social da Indústria (SESI) e a TV Escola (canal público do MEC), que disponibiliza um espaço interativo de estudo, com dicas, vídeos educativos, simulados on-line e um programa diário na TV Escola. Embora qualquer pessoa possa ter acesso a esse site, seu público-alvo é composto por jovens brasileiros que estão concluindo a Educação Básica e pretendem participar do Exame Nacional do Ensino Médio (ENEM), atualmente, o principal exame para o ingresso no Ensino Superior no país. Tendo em vista o objetivo dessa iniciativa, é imprescindível que o site seja atrativo e 
dinâmico, utilizando de maneira pertinente recursos do hipertexto e da multimodalidade.

\section{A leitura de textos multimodais}

As formas de interação mudam conforme as necessidades sociais. O desenvolvimento tecnológico fez emergir necessidades novas à sociedade, o que implica transformações nas formas de interação. Devido à sua natureza social, as formas de interação materializadas em textos passaram por grandes mudanças. Diante disso, tornase necessário rever o conceito de letramento, que está diretamente relacionado a essas formas de interação.

Segundo Soares (2004), letramento é o desenvolvimento - por meio do convívio com gêneros discursivos, tipos de texto e suportes diversos - de habilidades textuais em atividades de leitura e escrita necessárias à inserção nas mais diversas práticas sociais.

$\mathrm{Na}$ vida cotidiana, os sujeitos agem em diversas esferas de atividades humanas, assumindo diferentes papéis sociais, utilizando variados gêneros discursivos. Em cada uma dessas situações comunicativas, haverá práticas sociais diferenciadas. O conhecimento que permite o discernimento acerca da escolha e das formas de uso necessárias ao engajamento dos sujeitos nas diversas situações discursivas que emergem na vida social é resultado do letramento do indivíduo.

Em virtude da heterogeneidade das práticas sociais de leitura e escrita que foram desenvolvidas por uma sociedade letrada como a nossa, é preciso reconhecer a existência de múltiplos letramentos. Dessa forma, o conceito de letramento assume um caráter plural. Podem ser apontados letramentos institucionalizados (desenvolvidos em contextos formais de uso da linguagem, associados a sistemas legais, locais de trabalho, instituições burocráticas etc) e letramentos vernaculares (não controlados ou sistematizados por organizações sociais, pois se desenvolvem em culturas locais, na vida cotidiana).

Alguns aspectos relativos à questão do multiletramento devem ser ressaltados. Um deles se refere ao fato de que os letramentos institucionalizados tendem a ser dominantes, visto que, em relação ao conhecimento, são valorizados social e culturalmente; ao passo que os letramentos vernaculares são frequentemente desvalorizados e desprestigiados pela sociedade. Torna-se imprescindível desenvolver 
v. 7 (1)

434-448 jan/jun 2017

a compreensão de que esses tipos de letramento não deveriam ser considerados independentes, mas categorias interligadas.

Outro aspecto importante a ser ressaltado diz respeito às mudanças resultantes do surgimento e da ampliação de acesso a novas tecnologias digitais da comunicação, as quais têm levado a mudanças significativas nos usos da linguagem.

Rojo (2009, p. 105) adverte que:

por efeito da globalização, o mundo mudou muito nas últimas décadas. Em termos de exigências de novos letramentos, é especialmente importante destacar as mudanças relativas aos meios de comunicação e à circulação da informação.

São quatro as mudanças apontadas pela autora. A primeira delas consiste na intensificação e diversificação da informação nos meios de comunicação, que conduziram a transformações na maneira de ler, escrever e proporcionar a circulação social de textos. A segunda está relacionada à diminuição das distâncias espaciais, já que as distâncias geográficas foram minimizadas pelos transportes rápidos e pela rápida circulação de textos através de meios digitais. A terceira, intrinsecamente ligada à anterior, relaciona-se à diminuição das distâncias temporais, uma vez que a informação é capaz de atravessar enormes distâncias geográficas numa velocidade sem precedentes, quase instantaneamente. A última mudança apontada pela autora se refere à multiplicidade de modos de significar que o texto de mídias virtuais oferece.

Segundo Rojo (2009, p. 105-106),

já não basta mais a leitura do texto verbal escrito - é preciso relacioná-lo com um conjunto de signos de outras modalidades de linguagem (imagem estática, imagem em movimento, música, fala) que o cercam, ou intercalam ou impregnam; esses textos multissemióticos extrapolam os limites dos ambientes digitais e invadiram também os impressos (jornais, revistas, livros didáticos).

Em virtude dessas mudanças, é forçoso reconhecer a emergência de um novo tipo de letramento, o qual é exigido pelos textos contemporâneos, constituídos não só pela linguagem verbal, mas por recursos diversos, como imagens, músicas e outras semioses: o letramento multissemiótico.

A noção de letramento tradicional, ancorada no texto realizado apenas por meio da escrita, tem se mostrado insuficiente para compreender os diversos usos que os sujeitos sociais fazem da linguagem. 
Tendo em vista os recentes avanços tecnológicos, é imprescindível reconhecer que os textos atualmente produzidos têm utilizado, cada vez mais, diversos recursos semióticos (cores, imagens, sons etc), o que exige a análise desse novo tipo de letramento, necessário para agir sociocomunicativamente na vida contemporânea. A articulação entre diversos modos de realização, utilizando recursos verbais e não verbais, em um todo significativo, caracteriza a existência da multimodalidade.

Multimodalidade é a capacidade de um texto se constituir por diversos modos de linguagem, de forma que o sentido é construído com base na articulação textual estabelecida entre os diferentes modos de constituição do texto.

Dessa maneira, os gêneros multimodais se constituem como ações sociais que utilizam recursos além do signo verbal. A existência desses gêneros não é recente, contudo, nos últimos anos, em decorrência dos avanços tecnológicos, principalmente no que se refere às mídias virtuais, têm ocorrido mudanças significativas nos modos de representação de textos. Imagens, sons e palavras vêm estabelecendo uma relação cada vez mais interligada, a sociedade vem desenvolvendo cada vez mais textos com recursos verbais, visuais e sonoros.

De acordo com Dionísio (2009, p. 14), "os avanços tecnológicos têm colaborado e muito para esse jogo de experimentação de arranjos no processamento textual". Essas mudanças na construção desses gêneros discursivos, conforme enfatiza a autora, implicam também mudanças na forma de lê-los.

O uso de imagens, cores, novas disposições gráficas não se constitui como um mero enfeite, esses elementos se integram aos signos verbais na construção dos sentidos. Os sujeitos têm contato, desde muito cedo, com gêneros discursivos muito diversos, muitos dos quais inseridos num universo multimodal.

De acordo com Vieira (2007, p. 09), "o ritmo das inovações tecnológicas da pós-modernidade, sem precedentes na história, provocou profundas mudanças e alterações na linguagem escrita".

Essas alterações estão profundamente relacionadas às mídias e aos modos de comunicação desenvolvidos nas últimas décadas, os quais têm permitido a utilização de sofisticados recursos multimodais.

Conforme explica Vieira (2007, p. 09),

em face dessas transformações, a linguagem adapta-se às características da atualidade mundial, cujos avanços em tecnologia tornam algumas formas de escrita obsoletas. Em 
v. 7 (1)

434-448

jan/jun

2017 decorrência disso, a linguagem escrita reflete essas mudanças nos diferentes gêneros discursivos.

Contraditoriamente, muitos estudos científicos na área de linguagem têm se concentrado quase exclusivamente na oralidade e na escrita, como se a comunicação se restringisse a essas modalidades da língua. As práticas comunicativas diárias têm mostrado que é insustentável essa visão de que a construção dos sentidos, na atividade de leitura, ocorre apenas por meio da língua oral e escrita.

É necessário desenvolver, nos mais diversos leitores, a consciência de que o foco na língua oral e escrita é insuficiente para ler e interpretar os variados gêneros discursivos que circulam socialmente, os quais têm combinado vários modos semióticos.

Convém ressaltar que "não se trata de apenas pôr juntas palavras e imagens num texto, mas sim que se observem certos princípios de organização de textos multimodais" (DIONísIO, 2008, p. 129).

É cada vez mais importante dominar a leitura desses textos multimodais, visto que eles têm circulado socialmente de forma intensa e são, portanto, necessários para garantir aos sujeitos o direito de se inserir, como cidadãos, em práticas sociocomunicativas concretas.

\section{Os recursos multimodais no site Hora do ENEM}

Uma vez que vivemos em uma sociedade que utiliza cada vez mais diversos recursos tecnológicos, promovendo diversas formas de manipulação dos textos utilizados pelos sujeitos para interagir socialmente, é imprescindível investigar como a multimodalidade se apresenta como traço constitutivo desses textos.

A organização multimodal apresenta diferentes níveis de manifestação, o que conduz a uma necessidade de reconhecimento de que existe um contínuo de informação multimodal nos diversos textos que circulam socialmente, indo do menos informativo ao mais informativo. Para que se possa determinar o nível dessa organização multimodal, os elementos que compõem o texto podem ser analisados de acordo com vários critérios, contudo, dada a limitação de espaço deste artigo, optamos por apresentar apenas a análise de dois princípios de composição de imagens apontados por Kress e van Leeuwen (2006, p. 177): valor de informação e saliência. 
Valor da informação

As zonas das imagens (direita e esquerda, parte superior e parte inferior, centro e margem) em que se encontram os elementos visuais representam diferentes valores informacionais. Assim, o posicionamento dos elementos visuais em um texto é importante para a construção do sentido.

O site analisado se organiza do seguinte modo: no topo da página, há um slide show em que se revezam três banners. Acima do slide show, encontra-se o menu, que apresenta sete links, dois dos quais são constituídos por logomarcas (uma da TV Escola e outra do próprio site Hora do ENEM), ao passo que os demais dão acesso a conteúdos do site: conheça, programa de TV, plataforma de estudo, MECFLIX, perguntas frequentes. Se o usuário clicar em TV Escola, será direcionado para outro site. Se clicar em Hora do ENEM, voltará ao topo do site, que funciona como tela inicial. Se clicar em qualquer um dos outros links, a página rolará para baixo, até a informação solicitada. Caso não queira escolher um link, o usuário pode também fazer uma leitura linear, rolando a página para baixo, o que dará acesso a todas as informações, na ordem em que os links foram apresentados: conheça, programa de TV, plataforma de estudo, MECFLIX, perguntas frequentes. No final da página, apresentamse as logomarcas das entidades responsáveis por realização, apoio, parceria e das redes de TV envolvidas no projeto. No rodapé da página, encontram-se três logomarcas: Roquette Pinto - comunicação educativa, Ministério da Educação e Brasil - Governo Federal.

A análise dessa organização permite constatar que, na parte superior do site, são utilizados mais recursos do hipertexto e da multimodalidade. É justamente no topo que se encontram os links por meio dos quais o usuário decidirá o percurso de sua leitura. É também onde há a parte visualmente mais rica da homepage: além de ser o local em que mais se encontram imagens, é a única parte do site em que há elementos em movimento.

De acordo com Kress e van Leeuwen (2006), os elementos apresentados na parte superior de um texto correspondem àqueles que, de algum modo, representam uma idealização, ao passo que os elementos colocados na parte inferior representam a realidade. Desse modo, os três banners colocados no topo da página correspondem ao "mundo ideal", àquilo que se quer promover, enquanto as logomarcas apresentadas ao final da homepage correspondem ao "mundo real", 
v. 7 (1)

434-448 jan/jun 2017

àquilo que se apresenta de modo mais concreto. É comum também que, em sites de eventos, projetos e afins, sejam colocadas as logomarcas das instituições e grupos responsáveis pelo trabalho realizado, constituindose como uma espécie de assinatura.

Figura 1 - Parte final da homepage

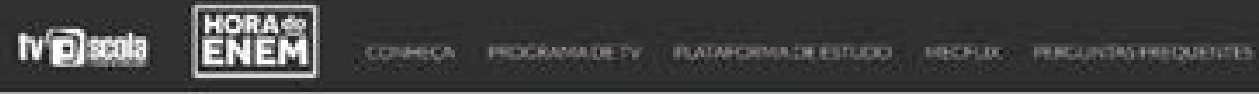

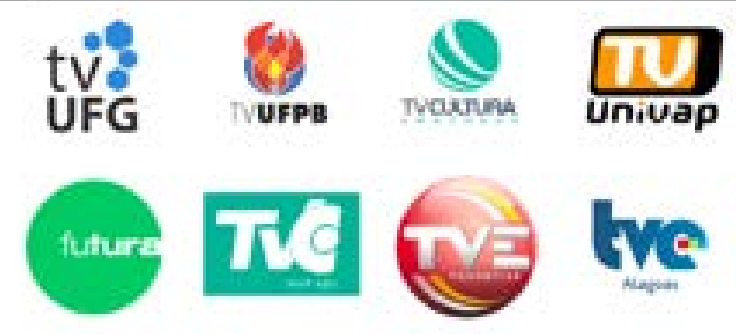

REDEMINAS

rogoltteginto
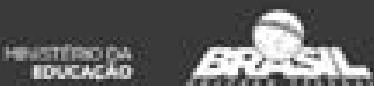

442

Segundo Kress e van Leeuwen (2006), a apresentação de elementos à esquerda ou à direita também é significativa, visto que os elementos colocados à direita são apresentados como um dado novo e os elementos colocados à esquerda representam a informação conhecida.

No primeiro banner, encontra-se uma imagem do programa de TV Hora do ENEM, exibido pela TV Escola. O plano de fundo é constituído pelo cenário do programa, composto por imagens diversas, as quais remetem à curiosidade (uma delas é constituída por um ponto de interrogação) e à construção do conhecimento (há imagens de mapas; de um cérebro dividido verticalmente ao meio, em que uma metade representa o próprio cérebro e a outra, uma máquina, um aparato tecnológico, que, assim, se compara ao cérebro; entre outras). O apresentador se encontra em primeiro plano, quase ao centro da tela. A informação nova, aquela que é colocada à direita, corresponde à explicação verbal da imagem, em que se encontra em destaque a expressão "Programa de TV", abaixo da qual se lê "Hora do ENEM na TV Escola". 
Figura 2 - Primeiro banner do slide show presente no topo do site

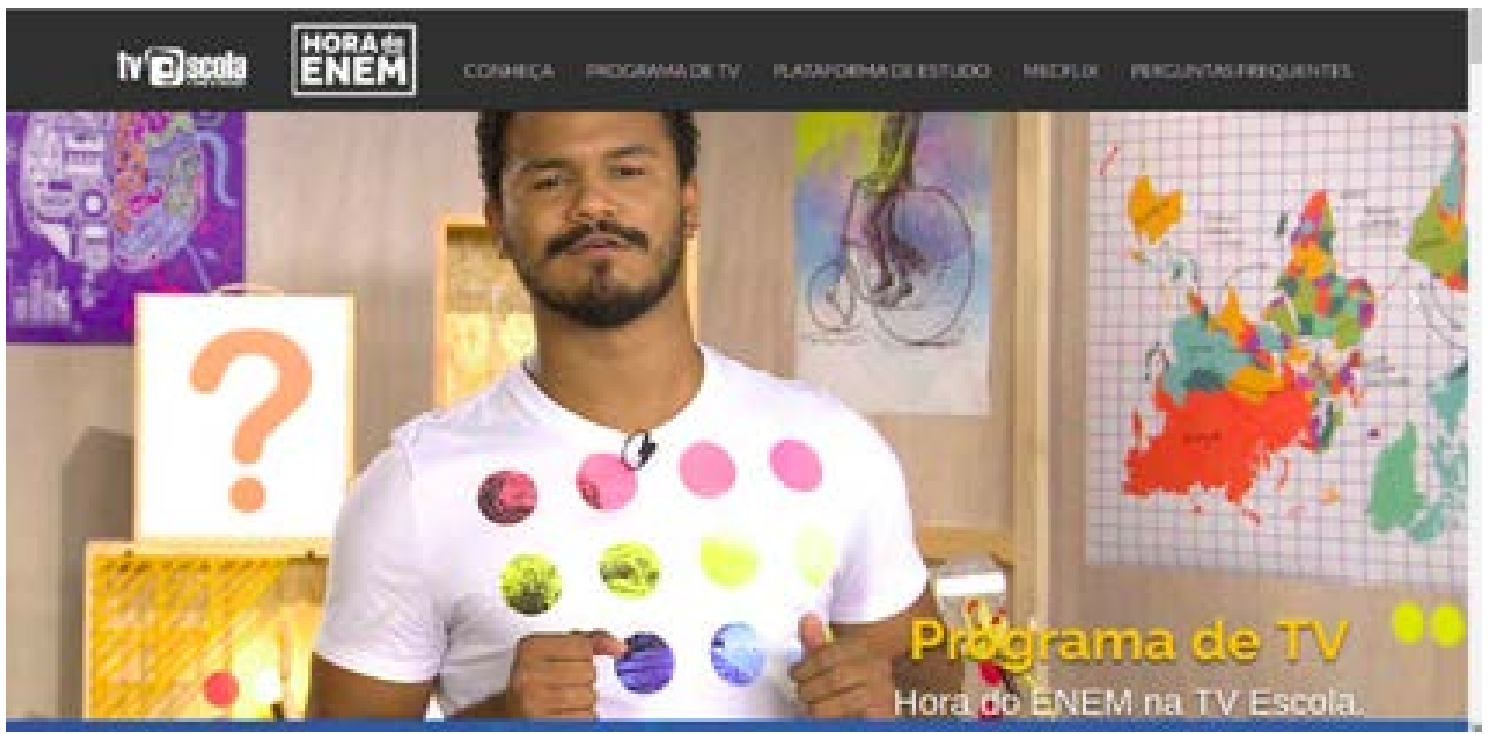

O segundo banner é constituído por um plano de fundo lilás, com imagem relativamente pouco nítida, no qual se encontram as informações verbais: a expressão "Fique ligado!", colocada à esquerda, constituindo-se como a informação dada; e a informação "Simulado Hora do ENEM - 25/Jun a 03/Jul", à direita, apresentada como o dado novo, no qual se destaca visualmente a logomarca Hora do ENEM. A imagem apresentada em posição central traz dois fios que se conectam por um plug (há um raio entre eles, representando a energia elétrica), o que é compatível com o sentido a ser construído com ajuda da informação verbal: ficar "ligado".

Figura 3 - Segundo banner do slide show presente no topo do site

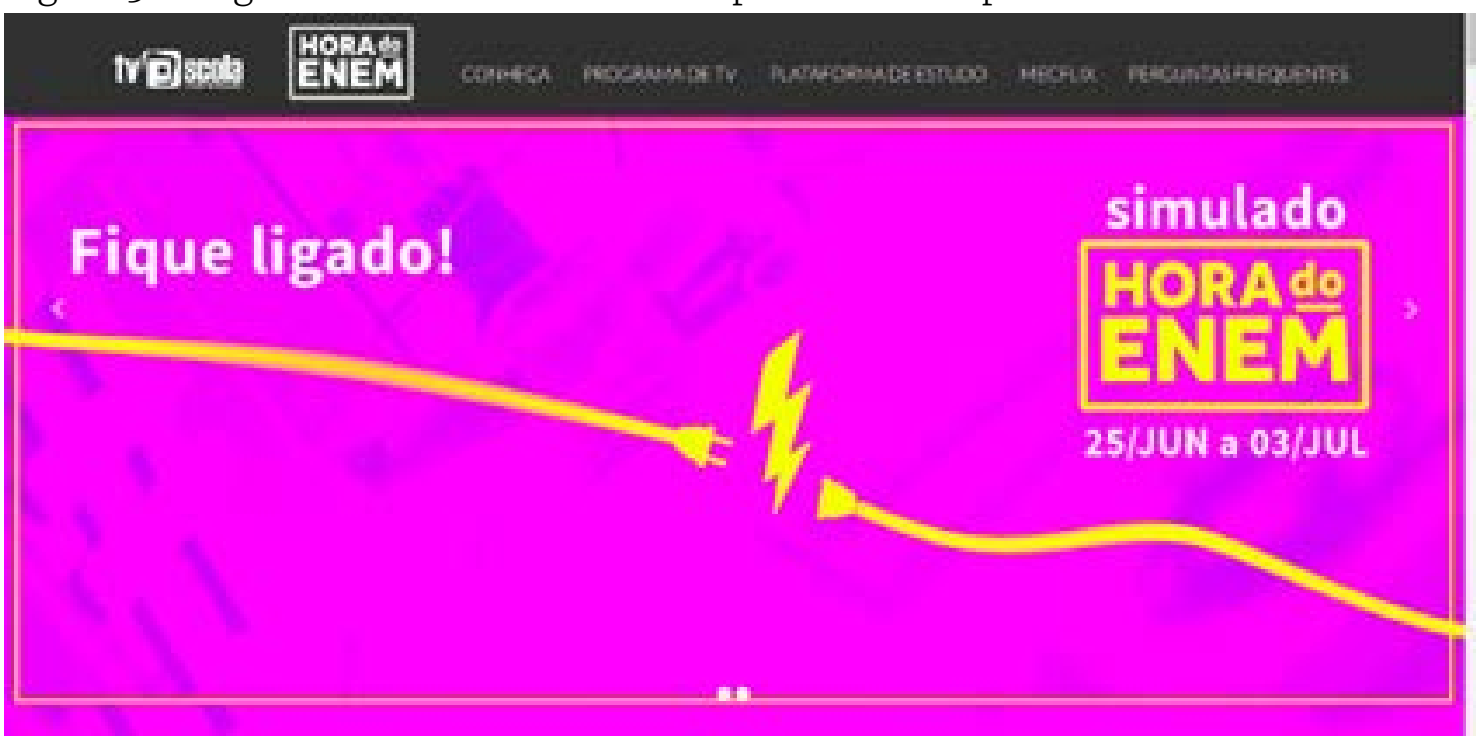

O terceiro banner apresenta um plano de fundo liso, cor de laranja. No centro da página, em posição superior, encontra-se a 
v. 7 (1)

434-448 jan/jun 2017 logomarca "Hora do ENEM", que, desse modo, apresenta-se como um elemento do "mundo ideal". Na parte inferior, que corresponde ao "mundo da concretude", encontram-se informações verbais e não verbais relativas à plataforma que vai ser efetivamente usada e aos aparelhos tecnológicos por meio dos quais o usuário pode conectar-se à plataforma. A informação verbal, colocada à esquerda, é apresentada como a informação dada, ao passo que a informação não verbal (uma imagem de três aparelhos de celular) é apresentada como o dado novo.

Figura 4 - Terceiro banner do slide show presente no topo do site

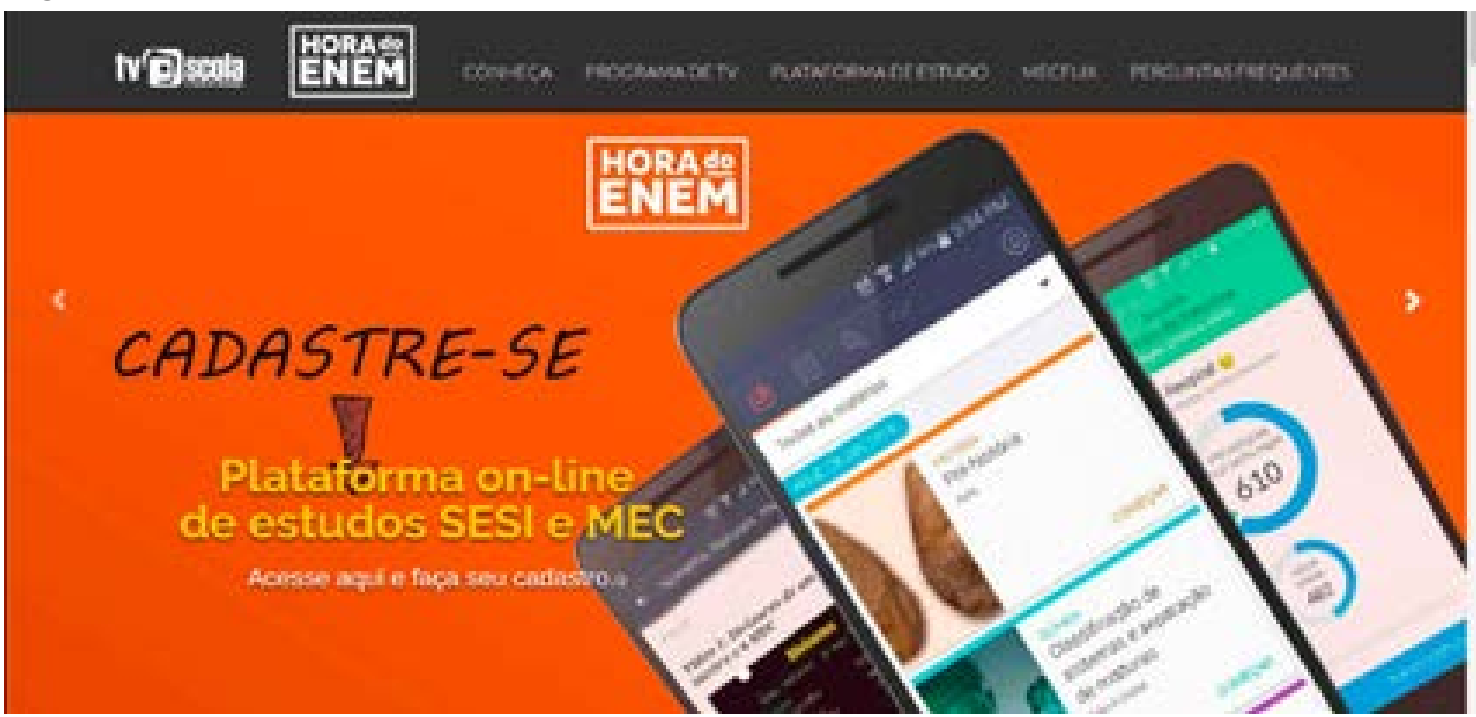

No restante do site, observa-se a predominância de informações verbais. Quando há imagens, a informação verbal é colocada como elemento central, em destaque, ou como o dado novo, visto que se apresenta à direita das imagens.

Figura 5 - Conheça

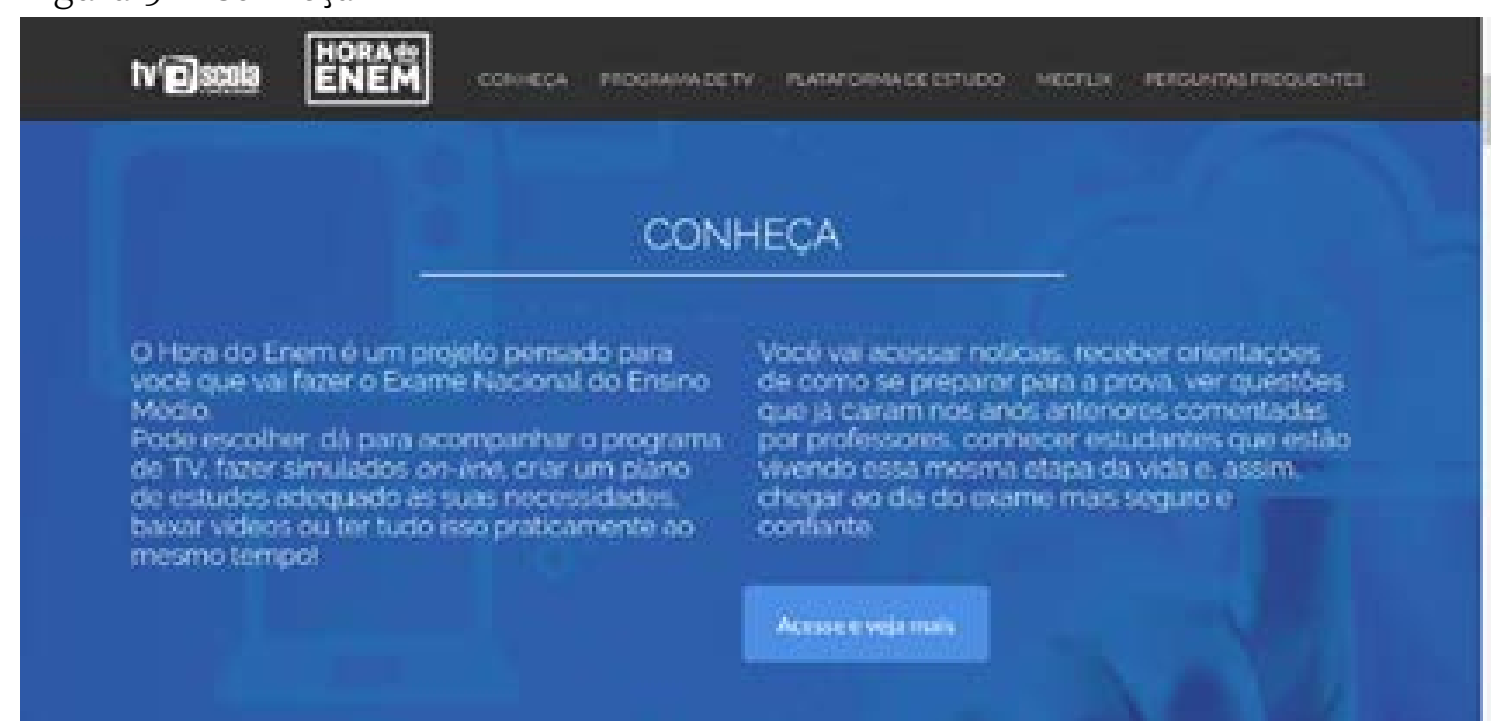


Saliência

A colocação de imagens no plano de fundo ou no primeiro plano, o tamanho das imagens, o contraste de tons e cores, os níveis de nitidez são fundamentais para estabelecer uma hierarquia de importância entre os elementos visuais.

No primeiro banner que compõe o site Hora do ENEM (figura 2), a saliência recai sobre a imagem do apresentador, que, além de se encontrar em primeiro plano, se constitui como o participante de maior destaque na imagem.

De acordo com Kress e van Leeuwen (2006), é possível reconhecer, em imagens com representações narrativas, dois tipos de participantes: participantes interativos e participantes representados. Os primeiros são os participantes do próprio ato de comunicação, os interlocutores, aqueles que escrevem ou leem, que falam ou ouvem, que produzem imagens ou as visualizam etc. Já os últimos são aqueles que se constituem como o objeto representado na imagem: podem ser pessoas, animais, coisas, lugares etc. Geralmente, em uma imagem, há um participante representado sobre o qual recai a ênfase, uma vez que se torna o elemento mais marcante devido a tamanho, contraste com saturação do fundo, cor, visibilidade, local na composição, nitidez ou destaque psicológico que certos tipos de participantes têm em relação aos demais.

Desse modo, no primeiro banner, o apresentador é o participante representado de maior destaque, não só por contraste, local na composição, visibilidade, mas também pelo destaque psicológico que a figura humana conquista quando comparada a participantes que não são humanos. Além disso, o apresentador da TV Escola se sobressai porque se está diante daquilo que Kress e van Leeuwen (2006) classificaram como uma imagem de demanda, visto que o olhar desse participante representado está diretamente voltado para o visualizador, que é explicitamente abordado como "um você visual". Assim, um contato é estabelecido entre o participante representado e o visualizador.

No segundo banner (figura 3), a saliência recai sobre a imagem dos fios que se encontrarão e sobre o raio de eletricidade. A ênfase é construída a partir do contraste dos fios e do raio de cor amarela com o plano de fundo lilás. Além disso, esses elementos são mostrados com definição, ao passo que as imagens que compõem o plano de fundo não têm total nitidez. Por fim, observa-se que os fios, de certo modo, 
v. 7 (1)

434-448 jan/jun 2017 perpassam a imagem, encontrando-se no centro, o que leva à percepção de que eles estão presentes no "todo" e gera a sensação de movimento.

No terceiro banner (figura 4), apesar da existência de uma seta que aponta para um link, a saliência recai sobre a imagem de três aparelhos de celular. Embora a seta pudesse contribuir para que o link ganhasse maior destaque na imagem, os aparelhos de celular se sobressaem no plano de fundo, marcando maior contraste. Eles também se constituem como o elemento de tensão da página.

Segundo Dondis (2007), a referência visual mais forte para a percepção humana é o equilíbrio. Assim, segundo esse autor, na interpretação visual, o ser humano impõe às coisas um eixo vertical com um referente horizontal secundário, o que se denomina eixo sentido. Todo objeto que se encontra fora desse eixo sentido estabelece uma tensão, o que chama mais atenção do observador.

Dessa maneira, como a imagem dos aparelhos de celular, ao ser colocada mais para a direita, não se ajusta ao eixo sentido, perturba o equilíbrio da página e chama mais atenção daqueles que a visualizam.

Em outras partes do site, a saliência recai sobre elementos verbais cujo destaque se deve ao contraste com o plano de fundo com imagens não tão nítidas, contraste em relação à cor do plano de fundo e ao tamanho maior das letras. Em algumas partes (plataforma de estudo e MECFLIX), encontram-se imagens estáticas, colocadas à esquerda da página, nas quais recai a saliência.

Figura 6 - MECFlix

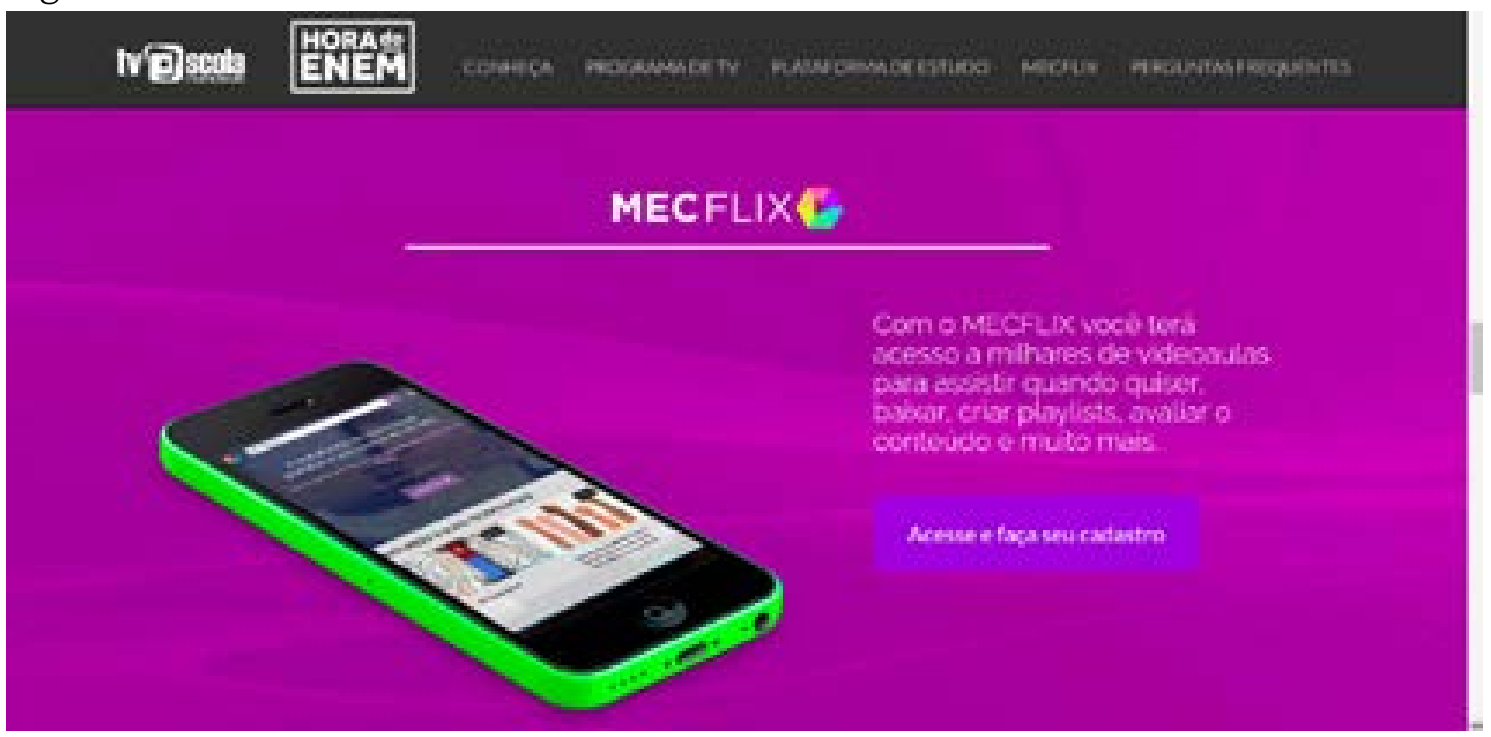




\section{Considerações finais}

Em uma sociedade letrada como a nossa, é fundamental que o leitor domine habilidades de leitura que permitam a compreensão dos diversos textos de seu convívio social, entre os quais se destacam gêneros do ambiente virtual.

Logo, não basta o domínio do sistema linguístico, pois não se pode ignorar a presença da multimodalidade em diversos textos de ampla circulação social. Afinal, é inegável a abundância de textos que utilizam mais de um modo de realização, de maneira que são frequentes os textos que se realizam por meio da utilização de signos verbais e recursos visuais, sendo estes, não raras vezes, considerados mais atraentes e mais informativos pelos leitores letrados.

A análise do site Hora do ENEM nos permitiu constatar que, uma vez que os recursos multimodais no hipertexto são constitutivos do sentido, poderia haver um investimento maior no diálogo entre recursos verbais e não verbais nesse espaço virtual. O site mostra-se bastante pertinente ao representar o mundo ideal e o real, todavia, ao realizar escolhas relativas a valores informacionais, o posicionamento dos elementos revela maior ênfase nos elementos de caráter verbal.

Assim, observamos que, na representação do mundo ideal, no topo da página, o site investe nos recursos do hipertexto e da alta modalidade: os links foram colocados em uma barra superior e existem imagens em movimento (os banners, que são a parte visualmente mais rica do site). Na representação do mundo real, na parte inferior da homepage, os responsáveis pela iniciativa que deu origem ao site são mostrados por meio da apresentação da logomarca das instituições.

No que diz respeito à valoração da informação, constatamos que o site, com raras exceções, privilegia o componente verbal, predominantemente apresentado como dado novo (à direita) ou como elemento central (de maior destaque). Em algumas partes do site, sequer se encontram imagens, os recursos visuais utilizados restringem-se às cores das letras e do plano de fundo e aos diferentes formatos das letras.

Embora o site funcione como uma espécie de "ponte" para que o aluno acesse outros portais (TV Escola, Plataforma de Estudo, MECFlix etc), acreditamos que ele poderia investir mais na utilização de recursos multimodais, visto que a presença de mais imagens, de vídeos, entre outros recursos, poderia colaborar para que se alcançasse com maior efetividade o objetivo do site: atrair o interesse de estudantes que desejam participar do ENEM. 
v. 7 (1)

434-448 jan/jun 2017

Compreende-se, portanto, por que a articulação entre signos verbais e elementos visuais precisa ser considerada na atividade de construção de sentidos, a fim de que os textos produzidos cumpram seu papel sociocomunicativo numa sociedade cada vez mais marcada por novos meios de comunicação, pelo uso intenso de múltiplas tecnologias de informação, que possibilitam um uso profícuo dos recursos do hipertexto e da multimodalidade.

\section{Referências}

CAVALCANTE, M. C. B. Mapeamento e produção de sentido: os links no hipertexto. In: MARCUSCHI, L. A.; XAVIER, A. C. S. (orgs.). Hipertexto e gêneros digitais: novas formas de construção do sentido. Rio de Janeiro: Lucerna, 2004.

DIONÍSIO, Â. P. Diversidades de ações sociais e de representações: diversidade de gêneros e em gêneros. Disponível em: <http://www. universidadedombosco. com.br/colegio/pdf/IICONGRESSO.pdf\#page =11>. Acesso em: 20/05/2009.

Gêneros multimodais e multiletramento. In: KARWOSKI, A. M.; GAYDECZKA, B.; BRITO, K. S. (orgs.). Gêneros textuais: reflexões e ensino. 3. ed. rev. Rio de Janeiro: Nova Fronteira, 2008.

448 DONDIS, D. A. Sintaxe da linguagem visual. Trad. de Jefferson Luiz Camargo. 3. ed. São Paulo: Martins Fontes, 2007.

KRESS, G.; VAN LEEUWEN, T. Reading images: the grammar of visual design. 2. ed. London: Routledge, 2006.

ROJO, R. Letramentos múltiplos, escola e inclusão social. São Paulo: Parábola Editorial, 2009.

SOARES, M. Letramento e alfabetização: as muitas facetas. Revista Brasileira de Educação. Rio de Janeiro, n. 25, p. 5-17, jan./abr. 2004. Quadrimestral. ISSN 1413-2478.

VIEIRA, J. A. Novas perspectivas para o texto: uma visão multissemiótica. In: VIEIRA, J. A. et al.. Reflexões sobre a língua portuguesa: uma abordagem multimodal. Petrópolis, RJ: Vozes, 2007.

Recebido em: 21 de fev. de 2017.

Aceito em: 29 de jul. de 2017. 